ISSN 1676-3742

\title{
A Igreja e seus ministros. Uma teologia do ministério ordenado
}

\author{
TABORDA, F., São Paulo, Paulus, 2011
}

(325 páginas)

Mario de França Miranda

Esta obra representa sem dúvida um importante subsídio para uma compreensão adequada do ministério ordenado. Consegue com grande maestria aliar didática, rigor, clareza, erudição e atualidade, conhecimento das fontes e sensibilidade para com a atual situação do clero. Temos em mão uma obra que significa o fruto de muitos anos de ensino, síntese madura de toda uma caminhada. Não encontramos facilmente um livro desta qualidade nos últimos anos.

Já na introdução aparece uma afirmação que marcará toda a obra e já explica seu próprio título: "o ministro existe para a Igreja e em função da Igreja e, por isso, a Igreja vem primeiro". Porque a prioridade do ministério sobre a Igreja acarreta a compreensão do mesmo como poder, ao passo que, em caso contrário, se destaca a comunidade eclesial como sujeito ativo dotada de muitos carismas, entre os quais o carisma do ministério ordenado. Também a etimologia do termo "ordem" ajuda-nos a entender que a ordenação significa ser recebido num colégio de ministros (ordem presbiteral). Ainda na introdução o autor expõe seu método de estudo: partir da celebração para encontrar seu sentido (lex orandi-lex credendi). Como porém, a passagem dos anos modificou o que deviam ser as celebrações, fez-se mister recuperar seu sentido autêntico através do testemunho da Escritura e da Tradição.

A obra está dividida em três grandes partes. A primeira busca nos oferecer uma base segura de cunho escriturístico e patrístico para a temática. A segunda nos apresenta uma reflexão sistemática da mesma. A terceira parte trata da 
estrutura e dos elementos essenciais da ordenação. O primeiro capítulo da primeira parte intitulado "a prática ministerial na Igreja à luz da atuação de Jesus" começa demonstrando que a atuação de Jesus não foi sacerdotal, ao confrontá-la com a função dos sacerdotes nas outras religiões e mesmo na religião mosaica, ao desabsolutizar a ordem sagrada, ao indicar que sagrado é o ser humano, que é histórico, mutável. Deste modo Jesus relativiza as pessoas sagradas, o tempo sagrado e o espaço sagrado. Na Carta aos Hebreus, Cristo é apresentado como fim e realização do sacerdócio, não cúltico, mas existencial, construído ao longo de sua vida histórica. Esta noção de sacerdócio de Cristo é desenvolvida em seguida pelo estudo da práxis de Cristo como a práxis do "Servo de YHWH", onde não há lugar para o poder mundano, mas para o poder na fraqueza, melhor caracterizado como exousía (autoridade). Deste modo conclui o autor ser ambígua a designação de "sacerdote" no cristianismo, aconselhando-nos a evitá-la. Ainda neste capítulo o autor aponta as consequências do que foi exposto para o ministério na Igreja. Aí emerge o poder como serviço que dá espaço para o outro, o governo na Igreja não como de cunho aristocrático ou democrático, mas pneumatocrático e fraterno, a saber, todos são sujeitos ativos, todos devem colaborar, todos são irmãos, todos são sacerdotes, um ministério a ser exercido como serviço ao outro. Entretanto, aos poucos, foi sendo introduzida a designação de sacerdote para o ministro ordenado, cujas razões são abordadas pelo autor, embora o Concílio Vaticano II prefira o termo presbítero ao termo sacerdote. Termina este capítulo a sugestão de considerar o ministério na Igreja segundo o modelo do Bom Pastor. O capítulo seguinte aborda o difícil e complexo tema dos ministérios no Novo Testamento. Primeiramente são expostos e caracterizados os ministérios básicos (apóstolos, profetas, doutores), em seguida os ministérios responsáveis pela estruturação das comunidades, que se apresentam diversamente nas Igrejas, mas que se influenciam mutuamente e tendem para o tríplice ministério (epíscopos, presbíteros e diáconos). O terceiro capítulo apresenta a evolução histórica na compreensão do ministério ordenado. No primeiro milênio predominou a concepção pneumatológico-eclesial. A imposição das mãos é feita em vista da comunidade local onde o ordenando desempenhará seu ministério e, por esta "incardinação" a esta comunidade a imposição das mãos adquire sentido. Assim ordenações absolutas não são admitidas, como afirma categoricamente o Concílio de Calcedônia (451). O que está subentendida nesta medida é que há uma reciprocidade entre o ministério ordenado e a comunidade local. Como preside a comunidade deve presidir também a 
celebração eucarística. A comunidade escolhe seu bispo, mas este só se torna tal pela ordenação (ação de Cristo Ressuscitado). Assim é a Igreja logicamente anterior ao ministério. Já pelo final do século XII começa uma mudança radical: a teologia afirma ser válida a ordenação desde que se respeite sua matéria e forma, deixando em segundo plano a comunidade local. Generaliza-se assim a prática de ordenações absolutas no Ocidente devido a vários fatores. Assim se introduz o conceito de "poder" do direito romano, embora inadequado para o ministério neotestamentário por ser uma categoria política. Então o ministério passa a ser considerado não mais na Igreja, mas para a Igreja. Outros fatores são: a querela das investiduras que enfatiza o poder da Igreja, a distinção entre poder de ordem e poder de jurisdição (na ordenação só se recebe o primeiro), a crescente clericalização observada nesta época junto com uma privatização da missa, vendo no ministro ordenado aquele que pode consagrar, que se distingue dos não ordenados, que age in persona Christi, que é dotado de um caráter sacramental. O ministro ordenado deve aplicar-se ao bem de uma comunidade; deste modo o ministério é logicamente anterior à Igreja. O Concílio de Trento separa o que é pastoral do que é doutrinal e apresenta assim uma dupla teologia do sacramento da ordem: uma baseada no conceito de sacerdócio e outra construída em torno da ideia de hierarquia. Esta última acaba por prevalecer. A outra foi vislumbrada pelo Concílio (volta à concepção do primeiro milênio), mas não conseguiu se impor. Vingou a versão doutrinal, cristológica que concebe o ministro ordenado de modo privatizante e sem relação com a comunidade. O Concílio Vaticano II tenta então uma síntese superando a concepção medieval em três pontos: a dicotomia entre poder de ordem e poder de jurisdição integrados no poder sagrado, que é entendido a partir do tríplice múnus e a visão do ministério a partir do episcopado. Entretanto esta conquista ainda não foi suficientemente "recebida" nos anos posteriores.

A segunda parte do livro nos oferece em dois capítulos uma exposição de cunho mais sistemático. No primeiro se aborda o que há de comum a todo ministério eclesial, tendo sempre como ponto de partida a comunidade eclesial. Primeiramente são apresentados os elementos constitutivos da Igreja Local com base no Decreto Christus Dominus do Concílio Vaticano II, mas ressaltando que a Igreja está sempre diante do mundo e também no mundo, daí ser santa e pecadora, bem como sempre em processo de reforma. Em seguida vem a exposição do que é comum a todos os batizados, importante para uma compreensão autêntica do ministério ordenado. A tríplice função já mencio- 
nada é comum a todos os membros da comunidade e definem a missão da Igreja. Entretanto cada um dela participa conforme o seu carisma. Daí ser a Igreja Local uma comunidade diversificada que respeita o carisma de cada um. Um deles é o carisma da direção ao qual cabe a função de presidir em vista da unidade. Assim é o ministério ordenado um carisma entre outros, um carisma em vista de outros carismas. Em seguida é tratado o tema do ministério ordenado, cujo serviço é comparado ao de um maestro de orquestra que deve coordenar os vários integrantes na fidelidade à partitura musical, no caso a Palavra de Deus. Assim o ministro não anula os demais carismas, mas conclama a todos da comunidade a fazer frutificar os próprios carismas. Porque preside a comunidade é responsável pela proclamação da Palavra e pela administração dos sacramentos, sempre em vista da unidade. O ministro ordenado é membro da comunidade, está $n a$ comunidade, mas também se situa diante da comunidade. A autoridade (exousía) de Cristo está no Corpo todo, mas enquanto representa Cristo-Cabeça o ministro ordenado torna presente este poder de Cristo, que é sem mais serviço. Há assim uma identidade relacional entre ministros ordenados e Igreja. Aqui o autor apresenta consequências importantes desta afirmação que, entretanto, extrapolam uma simples recensão. Terminando esta parte dedicada ao ministério ordenado é abordada a relação entre ministros ordenados e não-ministros (sacerdócio ministerial e sacerdócio batismal). Aí é valorizada a opção do Vaticano II com relação ao sacerdócio comum dos fiéis, sendo então explicada de modo claro e convincente a distinção entre ambos os sacerdócios quanto à essência e não quanto ao grau (LG 10), como se orientam um ao outro, como a participação dos fiéis leigos/as na missão salvífica da Igreja se fundamenta no batismo e não necessita de um mandato da autoridade, já que é constitutivo e não funcional. O tema seguinte versa sobre a sucessão apostólica, que é uma visão diacrônica da comunhão das Igrejas. Dificuldades postas por ocorrências históricas pedem uma revisão da concepção tradicional mais divulgada. Deve-se partir da Igreja que é apostólica em suas quatro dimensões: apostolicidade da origem, da doutrina, da vida e do ministério, inter-relacionadas de modo que não se deve separar a última das outras. Esta visão tem um forte alcance ecumênico. Finaliza este capítulo a questão da vocação ao ministério ordenado. A iniciativa do sujeito (vocação) para o ministério ordenado é uma concepção recente por influência de uma mentalidade individualista. Pois a tradição nos mostra a iniciativa partir da Igreja, necessitada de ministros e que verifica no ordenando as qualidades exigidas para realizar seu múnus. A vida religiosa, que pressupõe uma vocação particular, e sua importância numa 
determinada época, acabou influenciando a tradição, resultando no que hoje podemos observar. O capítulo quinto trata mais diretamente da diversidade dos ministérios. O ministério episcopal é o mais fundamental da Igreja. Ao bispo compete uma função de presidência, termo de origem patrística. Deve zelar pela unidade da fé e estar em comunhão com as demais Igrejas; assim é agregado ao colégio episcopal. Em sua missão recebe a colaboração dos presbíteros e dos diáconos. O ministério presbiteral é primeiramente de cunho colegial e, derivadamente, individual. O presbitério existe em função do bispo, do qual o presbítero é membro. Assim os presbíteros não são indivíduos isolados com suas funções particulares, mas um colégio que participa da solicitude do bispo por sua Igreja. Esta preeminência ministerial do bispo vigora até o século IV quando começa a ser valorizada a figura do presbítero, que será considerado o sacerdote sem mais, já que tem poder de consagrar, ocasionando a perda do caráter colegial deste ministério. Mas permanece o fato de que o presbítero exerça sua missão em nome do bispo em suas respectivas comunidades (paróquias). O ministério diaconal existe em função e a serviço do bispo, ocupando-se do cuidado com os pobres e sofredores (solidariedade), além da missão da Palavra e da liturgia, estando estes três polos inter-relacionados. Assumindo assim o tríplice múnus da Igreja o diácono existe em função da construção da comunidade e não é um presbítero inferior já que goza de identidade própria que complementa o ministério episcopal e presbiteral. Também é tratada a questão do religioso presbítero que não pastoreia propriamente uma comunidade, criando assim uma situação anômala. Neste caso o autor expõe de modo denso e profundo o princípio da "economia", vigente na Igreja Oriental, e que corrige em parte a predominância do direito romano e germânico na Igreja Ocidental. Aplica-o a seguir ao caso dos presbíteros religiosos com sugestões que respondam ao problema. Outro tema que questiona a teologia do episcopado vem a ser a pessoa do bispo titular (auxiliar), já que não preside propriamente uma Igreja Local. $\mathrm{O}$ autor apresenta então algumas possibilidades que o justifiquem teologicamente.

Vista mais brevemente a terceira parte da obra trata da estrutura e dos elementos essenciais de uma ordenação, dividida em dois capítulos: a expressão significativa do sacramento da ordem ou quirotonia, seguido de outro capítulo com um estudo sobre as preces da ordenação. Primeiramente se mostra como a imposição das mãos com a prece da ordenação recebe todo o seu sentido à luz da tradição mais antiga da estrutura própria da ordenação. Tal sentido ganha mais força quando se expõem suas raízes antropológicas que 
buscam expressar a graça do sacramento. Entretanto o rito romano da ordenação sofreu mudanças que obscureceram seu sentido, sendo então restaurado pelo Concílio Vaticano II. O capítulo seguinte trata das preces da ordenação, orientadas pela lógica da aliança e baseadas na todá veterotestamentária e na tradição do judaísmo. Em seguida o autor nos oferece um estudo amplo e detalhado das preces de ordenação na liturgia romana atual, que abrange a parte histórico-teológica dos capítulos anteriores e demonstra como a lex orandi se fundamenta na Escritura e é praticada universalmente.

Ao final desta recensão reconhecemos que estas linhas não conseguem traduzir toda a riqueza deste livro. Didático, rigoroso, claro, fruto de uma pesquisa de muitos anos, deveria ser leitura indispensável para o clero, para os seminaristas, e também para os fiéis leigos/as. Com ele muito se aprende, não só a respeito do ministério ordenado, pois o autor nos brinda também com uma teologia sacramental atualizada e uma visão de Igreja na linha do Concílio Vaticano II. Agradecemos ao autor estes anos de estudo e de dedicação, pois muito recebemos de sua leitura.

Mario de França Miranda

Professor de Teologia na PUC-Rio Doutor em Teologia Sistemática pela Pontifícia Universidade Gregoriana

Resenha Recebida em 29/02/2012

Resenha Aprovada em 30/03/2012 